\title{
Major Causes of Acculturative Stress and Their Relations with Sociodemographic Factors and Depression among International Students
}

\author{
Werede Tareke Gebregergis \\ School of Psychology, Central China Normal University, Wuhan, China \\ Email: weredetarekeg@yahoo.com
}

How to cite this paper: Gebregergis, W.T. (2018) Major Causes of Acculturative Stress and Their Relations with Sociodemographic Factors and Depression among International Students. Open Journal of Social Sciences, 6, 68-87.

https://doi.org/10.4236/jss.2018.610007

Received: September 17, 2018

Accepted: October 22, 2018

Published: October 25, 2018

Copyright $\odot 2018$ by author and Scientific Research Publishing Inc. This work is licensed under the Creative Commons Attribution International License (CC BY 4.0).

http://creativecommons.org/licenses/by/4.0/

\begin{abstract}
The purpose of the study was to examine the main sources of acculturative stress and their associations with sociodemographic factors and depression. A descriptive cross-sectional research design was employed to investigate the study. International students $(N=506)$ volunteered to take part in the survey and completed two self-report questionnaires: Acculturative Stress for International Students Scale and a Center for Epidemiological Studies Depression Scale. Descriptive statistics, Pearson's product moment correlation, t-test, and analysis of variance were performed in data analyses. The study delineated that homesickness, culture shock, and discrimination were the leading stress causing factors among the students. Participants' age, marital status, Chinese language proficiency, friendship with local students, educational level, prior travel experience and source of financial support also appeared to have a significant association with their acculturative stress scores. The study also explored a significant positive relationship between acculturative stressors and depression. Findings of the study could apply to host universities to better engineer programs or services that accelerate and promote the psychological positive acculturative process and outcomes of their international fellow students and subsequently safeguard them from exacerbating mental health problems.
\end{abstract}

\section{Keywords}

Acculturative Stress, Sociodemographics, Depression, International Students

\section{Introduction}

Higher education internationalization has increasingly been growing in the last few decades diminishing the necessity for strict national educational context [1]. 
Consequently, millions of students around the globe travel from their home countries to other countries to pursuing their higher education. Therefore, international education exchange programs provide many reciprocal advantages for both the international students and the host country. International students get the chance of becoming part of the international learning environment, attaining higher levels of personal development and independence, and greater cultural awareness and competence. The diverse nature of the international students' population also enriches the multicultural awareness and appreciation of the host country [2]. Besides, the full range of multidisciplinary skills and knowledge of the students significantly enhances the intellectual capital and workforce and thereby the national economic development of the host country [3] [4]. However, international students also experience a wide range of challenges related to the process of acculturation in the new host culture that may lead to acculturative stress and tension [5] and depression [6]. Although acculturative difficulties seem to be a natural aspect of adjustment to the new environment, they can even develop into devastating mental health problems especially if there is a lack of clear understanding of the major acculturative stressors and their psychological impact. It is for this reason that the international students' population has been continuously drawing the attention of many researchers with the aim of establishing an accurate and comprehensive understanding of the adjustment issues of the students. Besides, for personal characteristics of individuals are claimed to compound their acculturative experiences, giving due consideration to sociodemographics in the acculturative studies could contribute to noticeably figuring out the acculturative circumstance of the students.

\subsection{Acculturative Stress}

Acculturation is a process in which an individual undergoes psychological changes as a result of unceasing first-hand contact with people of different cultures [7]. International students who experience accumulated pressure to adjust to a new language, to cultural values, as well as to social norms and the pressure may put a significant demand on individuals, increasing their feelings of stress or fear [8]. The reaction to those changes arising from the discrepancies between their native culture and the primary host culture is described as acculturative stress [7]. Acculturative stress is, therefore, a type of stress in which individuals come to experience and exhibit certain stress behaviors such as alienation, depression, anxiety, marginalization, heightened psychosomatic symptoms, and identity confusion [9].

\subsection{Major Sources of Acculturative Stress}

As acculturation is a very complicated process and the factors that lead to acculturative stress are multiple and convoluted as well. Following are among the factors that contribute to acculturative stress of international students.

Homesickness. Students' relocation and adjustment to the new host commu- 
nity leads to stress. Homesickness which encapsulates missing one's beloved families and friends, feeling of alienation, adjustment problems and home contemplations [10] was found to be among the leading acculturative stress causing factors in international students [11] [12]. Students who experience separation anxiety, longing for their family were found to have higher acculturative difficulties.

Prejudice and discrimination. Despite the benefits that host countries provide to the international students, they are also a source of symbolic and direct perceived discriminatory practices [13] which may make international students less interactive and participatory in activities of the host community and subsequently develop health problems such as psychological distress and alienation [14] [15].

Culture shock. Another common challenge that international students face is culture stress or culture shock that students feel disoriented towards the cultural practices of the host culture because of cultural incompatibility or culture distance. Culture shock was found to be a common problem among a majority of international students [16] [17].

Fear, guilt, and hatred. When international students move to the new sociocultural environment, they can experience both physical fear and fear of unknown because of the feeling of worries and insecurities [18]. Prejudice, negative stereotypes, intergroup anxiety, realistic threat and cultural threats concerning discrepancies in social values, morals, standards, beliefs, and attitudes were found to be the chief causes of threat for international students [19]. Sometimes, adherence to the sociocultural practices of the host country can make the international students feel guilty because of their understanding of betrayal to their native culture [18].

Miscellaneous. According to Sandhu and Asrabadi [20], there are also several general factors that additionally contribute to the international students' acculturative concern. Miscellaneous concerns include lack of confidence to communicate in the local language, feeling of intimidation to take part in social activities, lack of sense of belongingness to the host community, worries about what to do after completing one's study whether to go back home country or stay aboard.

\subsection{Depression}

According to American Psychiatric Association, as cited in [21], depression is a severe mental health problem characterized by loss of interest, depressed mood, low self-worth, sleep difficulties, poor concentration, feelings of guilt and low energy which unsympathetically affect person's thoughts, feelings, and actions. Depressive symptoms can be chronic and persistent and can lead to substantial impairments in an individual's ability to accomplish his or her day to day responsibilities. Depression is a widespread problem that can affect a wide range of groups such males, females, students, workers, adolescents [22], general tertiary education students' population [23] and international students [24]. 


\subsection{Review of Literature}

\subsubsection{Acculturative Stress and Sociodemographics}

Gender. The issue of gender and acculturative stress is not well-established, and findings are contradictory to one another. For instance, Berry, Kim [25] found that female students are more prone to acculturative stress than males. On the other hand, males were found to be more victim of acculturative difficulties [26]. In other several studies, gender was also found to have no significant association with acculturative stress (e.g., [27] [28]).

Age. Age is also one of the personal variables that influence acculturative stress. According to Berry [29], younger individuals are more likely to undergo through minimal acculturative difficulties because they are more flexible and open to integrating with the mainstream culture. However, Yeh and Inose [30] argue that because of their psychological and emotional immaturity, young people are more vulnerable to acculturative stress than the matured adults. Those results indicate that the issue of age and acculturative stress is not well-established as well.

Marital status. Because of mixed and debatable findings, there is no definite conclusion about the nature of the association between acculturative stress and marital status. According to Ahalya and Berry [31], unmarried individuals experienced greater acculturative stress than married ones, and the finding contradicted the finding of Yu, Chen [32].

Financial support. Financial difficulty is one of the factors that affect students' acculturative challenges. Based on the financial support, students can be classified into scholarship students or self-supporting students. Although there is a dearth of empirical studies on this issue, Akhtar and Kröner-Herwig [33] found self-supporting students to experience more acculturative stress than the scholarship students. Nevertheless, it seems that irrespective of the source of the support, insufficient financial support may hinder successful adjustment.

Language Barrier and Prior travel experience. Previous studies have invariably reported that language difficulty is negatively associated with acculturative stress, indicating that students with good host language proficiency better adapt to the new environment and experience less acculturative challenges (e.g., [8] [34]). Concerning prior travel experience, several research studies have indicated that students with prior travel experience less acculturative difficulties [8].

Educational level. In some studies, acculturative stress has also been found associated with the educational qualification of participants, indicating that bachelor students experience less acculturative stress than master and doctorate students [32].

Friendship with domestic students. Another important factor associated with acculturative stress is friendship with local students. Previous research works found that international students who have good social relations with the domestic students experienced less acculturative stress than those with no friends [35]. 


\subsubsection{Acculturative Stress and Depression}

Acculturative stress is one of the factors that lead to depression. Thus, studies on immigrants have revealed that acculturative stress and perceived discrimination were found to be associated with greater psychological distress [36]. Many overseas students' researches have widely reported that there is a positive association between acculturative stress and depressive symptoms among international students, showing that students with high level of acculturative stress are prone to depressive symptoms [37] [38].

In their systematic review of acculturative studies, Smith and Khawaja [3] have also reported that acculturative experiences of international students are associated with mental health problems that corroborated the finding of Hunley [39] that psychological distress and loneliness impede students' effective functioning in their study in abroad. Although the consistency of many findings on the linear relationship between acculturative stress and depression, Heine [40] argue that acculturative studies are self-contradictory, and generalization is difficult. Tiwari [41] also conducted a systematic review of the relationship between acculturative stress and mental health problems and reported that findings are mixed up and controversial. In a study investigated by Saad [42], international students were appeared to adapt and function effectively in the host community, and their mental health status was not found to be different from the domestic students. Therefore, what these results fundamentally reflect is that an accurate understanding of the nature of the relationship between acculturative stress and depression needs further investigation.

\subsection{Statement of the Problem}

Heine [40] has avowed that acculturative studies are self-contradictory and less empirically grounded asserting that there is a lack of complete and comprehensive explanation in the area of acculturation and mental health [3]. Besides, acculturative stress studies have mainly been carried out in North America, Australia and to some extent in Europe but mostly dark in Asia and Africa [8] [29] perhaps due to unavailability of a large body of international students' population. However, Chinese higher education internationalization has recently been swiftly growing making the country one of the top study destinations in the world attracting a huge number of overseas students. The fast-growing number of international students in China has opened a door for fresh acculturative investigations in the country. Despite the fresh research opportunity in the region, the research works on international students' mental health problems such as acculturative stress and mental health problems such as depression appeared to be significantly limited [37]. Similarly, Wen, Hu [43] stated both the national level and individual level research studies in China are far lagging behind. Hence, these results reflected that the trend of the research endeavors in the country is at its embryonic stage. Also, despite several studies documented that students' personal characteristics influence their acculturative stress, the nature 
of the association is still contradictory and mixed-up. Such limited empirical studies and controversies drew my attention to examine acculturative stress and its ties with sociodemographic variables and depression among international students in China.

\subsection{Research Questions}

1) What are the leading causes of acculturative stress among international students?

2) Do students' acculturative stress scores differ across their sociodemographic characteristics: gender, age, marital status, educational status, friendships with local students, source of financial support, and prior travel experience and chinse language?

3) What is the association of acculturative stress and its constituents with depression?

\section{Method}

\subsection{Research Design}

A quantitative research design was employed to examine the present study. Because investigating social science research problems using quantitative research design provides several advantages such as investigating large sample, enhancing the power of generalization of results, increasing results' objectivity and accuracy, compiling and synthesizing huge sources of information and making comparisons across categories and time and minimizing researcher's bias by keeping distance from the participants and recruiting unknown participants [44]. The current study also appeared to be a cross-sectional study in a way that variables were measured at a specific point in time.

\subsection{Participants}

The study was conducted among international university students in Wuhan, Hubei province, China. 506 volunteered students with a mean age of 27.32 were purposively selected from seven universities. The average length of stay of the participants in China was 21.70 months. Table 1 presented the detailed frequency distributions of the respondents of the study.

\subsection{Procedure}

In the process of data collection, self-report questionnaires were distributed among the participant students in their respective universities and classrooms. Some senior Master and Ph.D. students from the school of psychology, Central China Normal University, country mates, and friends were recruited in administering, guiding and facilitating the data gathering process in case participants may face difficulties in understanding the item statements. Participants were assured that data would not be used for any other purpose other than research 
purpose. Individual safety, respect, autonomy, data anonymous and confidentiality were seriously maintained as well.

\subsection{Measures}

\subsubsection{Sociodemographic Information}

To obtain information about the sociodemographic characteristics of the participants, self-designed questions on the target demographics were included along with the other measures of the study variables.

\subsubsection{Acculturative Stress}

To measure acculturative stress, Acculturative Stress Scale for International Students (ASSIS) developed by Sandhu and Asrabadi [20] was used. ASSIS is a 36-items self-report questionnaire rated on 5 points Likert type of scale, spreading from 1 (Strongly Disagree) to 5 (Strongly Agree). ASSIS encompasses seven subscales (see Table 2). Several previous research reports have agreed that ASSIS is a highly reliable instrument with a reliability coefficient ranging from 0.92 to 0.94 [37] [45]. The instrument was also validated using factorial analysis by Sandhu and Asrabadi [20]. In the current study, the reliability coefficient of the measure was found to be sufficient (see Table 2) except for sub-scale guilt, and this might be due to the few numbers of items.

\subsubsection{Depression}

To measure the prevalence of depressive symptoms among the student participants, a Center for Epidemiological Studies Depression Scale (CES-D) developed by

Table 1. Frequency distribution of participants' socio-demographic characteristics.

\begin{tabular}{|c|c|c|c|c|}
\hline Variables & Categories & $N$ & $\%$ & Total $(N)$ \\
\hline \multirow{2}{*}{ Gender } & Males & 284 & 56 & \multirow{2}{*}{504} \\
\hline & Females & 220 & 44 & \\
\hline \multirow{2}{*}{ Marital Status } & Married & 152 & 30 & \multirow{2}{*}{504} \\
\hline & Unmarried & 352 & 70 & \\
\hline \multirow{3}{*}{ Educational Status } & Bachelor & 152 & 30 & \multirow{3}{*}{506} \\
\hline & Masters & 206 & 41 & \\
\hline & Doctorate & 148 & 29 & \\
\hline \multirow{2}{*}{ Prior Travel Experience } & Yes & 308 & 61 & \multirow{2}{*}{504} \\
\hline & No & 194 & 39 & \\
\hline \multirow{2}{*}{ Source of Financial Support } & Scholarship & 391 & 77 & \multirow{2}{*}{505} \\
\hline & Self-support & 114 & 23 & \\
\hline \multirow{2}{*}{ Friendship with Chinese Students } & Yes & 359 & 71 & \multirow{2}{*}{506} \\
\hline & No & 147 & 29 & \\
\hline \multirow{4}{*}{ Chinese Language } & Poor & 196 & 39 & \multirow{4}{*}{506} \\
\hline & Fair & 175 & 34 & \\
\hline & Good & 110 & 22 & \\
\hline & Very good & 25 & 5 & \\
\hline
\end{tabular}


Table 2. Summary of Mean, SD and Alpha values $(\mathrm{N}=506)$.

\begin{tabular}{ccccccc}
\hline Subscales & No. of Items & Alpha & $\boldsymbol{M}$ & $\boldsymbol{S D}$ & $\boldsymbol{S k}$ & $\boldsymbol{K u r}$ \\
\hline Perceived Discrimination & 8 & 0.82 & 2.32 & 0.73 & 0.17 & -0.45 \\
Homesickness & 4 & 0.61 & 2.79 & 0.84 & -0.05 & -0.33 \\
Perceived Hate & 5 & 0.77 & 2.05 & 0.71 & 0.44 & -0.24 \\
Fear & 4 & 0.72 & 1.93 & 0.73 & 0.42 & -0.73 \\
Culture Shock & 3 & 0.57 & 2.48 & 0.84 & 0.31 & -0.17 \\
& & & & & & \\
Guilt & 2 & 0.46 & 2.09 & 0.90 & 0.60 & -0.25 \\
Miscellaneous & 10 & 0.74 & 2.23 & 0.61 & 0.11 & 0.13 \\
Total acculturative stress & 36 & 0.92 & 2.27 & 0.57 & -0.08 & -0.49 \\
Depression & 33 & 0.82 & 1.88 & 0.41 & 0.41 & -0.32 \\
& & & & & & \\
\hline
\end{tabular}

Radloff [46] was utilized. CES-D is a self-report instrument devised to measure depressive symptomatology such as depressed mood, the feeling of worthlessness, loss of appetite, poor concentration and sleep disturbance in the general population. CES-D contains 20 both positively and negatively worded items rated on 4 Likert type of scale which ranges between 1 (Rarely or none of the time) to 4 (All of the time). A widely used instrument, CES-D, has consistently been reported to have a high internal consistency ranging from 0.85 to 0.90 throughout several research studies [46]. Similarly, validity and reliability of the instrument was also ascertained by international students' studies (e.g., [45] [47]). In the current study, the inner consistency of the instrument was 0.82 (see Table 2).

\subsection{Data Analytical Procedure}

First data were inputted into a 21 version SPSS (Statistical Packages for Social Sciences). Then, frequency of distribution, mean and standard deviation were applied to summarize the data. Finally, t-test, one-way between-subjects analysis of variance and Pearson's correlation were employed to explore associations between the study variables.

\section{Results}

\subsection{Sources of Acculturative Stress}

To identify the leading factors that contribute the feeling of the acculturative stress of the students, means of mean scores for the seven subscales of acculturative stress scale for international students rated on five Likert scales stretching from 1 to 5 were computed.

As depicted in Figure 1, homesickness $(M=2.79, S D=0.84)$, culture shock $(M=2.48, S D=0.84)$ and perceived discrimination $(M=2.32, S D=0.73)$ were found to be the top three leading sources of acculturative stress whereas perceived hate $(M=2.05, S D=0.71)$ and fear $(M=1.93, S D=0.73)$ were reported to be the least stressors. 


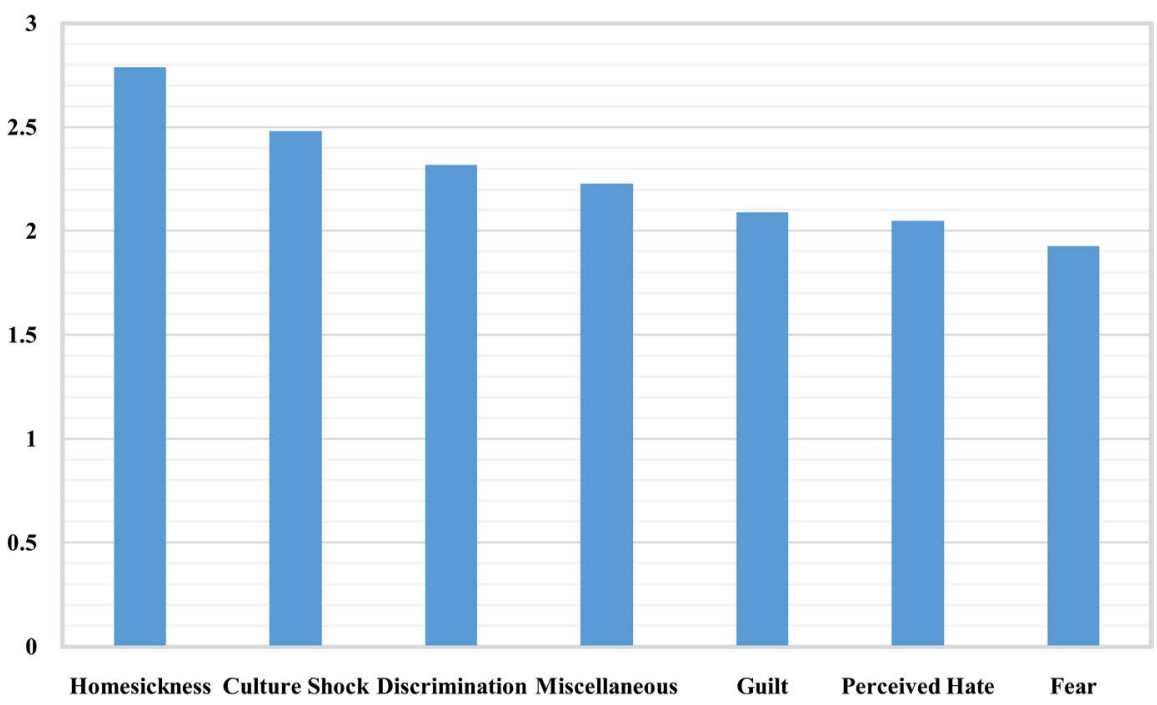

Figure 1. Rank of the sources of acculturative stressors.

\subsection{Distribution of the Scores of the Data}

To assess the assumption of normality for the study variables, measures of distribution shape, skewness and kurtosis were calculated. The range of values for skewness and kurtosis between -2 and +2 are considered as acceptable limits to prove the normal univariate distribution [48] [49]. Therefore, the values of skewness and kurtosis for the present study variables (see Table 2) fell within the acceptable range, reflecting that data were normality distributed.

\subsection{Associations between Socio-Demographic Factors and Acculturative Stress}

To examine whether acculturative stress statistically significantly differed across different sociodemographic categories, independent-sample t-test, $\mathrm{F}$ test and correlation were computed.

\subsubsection{Gender}

An independent sample t-test was conducted to compare the acculturative scores for males and females. No statistically significant difference was detected in the scores for males $(M=2.30, S D=0.58)$ and females $(M=2.23, S D=0.56) ; t(502)$ $=1.39, \mathrm{p}=0.17$, two tailed. The size of the difference between the two means (mean difference $=0.07,95 \% C I$ : -0.03 to 0.17 ) was very small (Eta squared $=$ 0.004). Besides, the assumption of homogeneity of variance was tested via Levene's F-test and no violation of assumption was occurred $F(502)=0.03, \mathrm{p}=0.861$.

\subsubsection{Marital Status}

Compared their mean scores, the mean values for married participants $(M=$ 2.38, $S D=0.56)$ was found to be greater than their unmarried counterparts $(M=$ $2.22, S D=0.56$ ). To test whether the difference was statistically significant, $\mathrm{t}$-test was calculated. The calculated t-test indicated that there was significant difference in acculturative scores for married and unmarried $t(502)=3.02, \mathrm{p}=0.003$, 
two tailed. The degree of the difference between the means (mean difference $=$ $0.017,95 \%$ CI: 0.06 to 0.27 ) was small (eta squared $=0.017$ ) as per the guideline for interpreting effect size proposed by Cohen [50]: 01 (small effect), 06 (moderate effect) and 0.14 (larger effect). Additionally, Levene' $\mathrm{F}$ test for equality of variance indicated no violation of assumption of homogeneity $F(502)=0.050, \mathrm{p}$ $=0.823$.

\subsubsection{Prior Travel Experience}

To examine whether previous abroad travel experience affects acculturative stress, an independent sample test was run. The calculated t-test showed that students who never travelled abroad before coming to China $(M=2.42, S D=$ 0.54 ) were found to significantly differed in their acculturative stress score from those with previous travel experience $(M=2.18, S D=0.57) ; t(500)=4.42, \mathrm{p}=$ 0.000 . Meaning that students with previous travel experience reported less acculturative stress than their counterparts. The degree of the difference between the means (mean difference $=-0.23,95 \% C I$ : -0.32 to -0.13 ) was small (eta squared $=0.038)$. The assumption of equality of variance was also satisfied $F(500)=1.03, \mathrm{p}=0.312, \mathrm{p}>0.05)$.

\subsubsection{Source of Financial Support}

The mean score of acculturative stress for scholarship students $(M=2.29, S D=$ $0.56)$ was higher than the self-support students $(M=2.17, S D=0.58)$ and the difference was statistically significant $t(503)=1.98, \mathrm{p}=0.048, \mathrm{p}<0.05)$. The strength of the relationship between the means was very small (mean difference $=0.06,95 \% C I: 0.00$ to 0.24 , Cohen's $d=0.008$ ). Further, Levene's test of homogeneity revealed that equality of variance was assumed $F(500)=1.99, \mathrm{p}=0.656$, $\mathrm{p}>0.05)$. Therefore, the result designated that scholarship students are more like to experience higher level of acculturative stress than the self-support ones.

\subsubsection{Friendship with Chinese Students}

More importantly, international students who maintained good friendship with local students were found to have lower mean scores $(M=2.23, S D=0.59)$ than the students with no local friends $(M=2.35, S D=0.51)$ for acculturative stress. To test the whether the difference was statistically significant, t-test was computed and significant difference was detected $(t(504)=2.03, \mathrm{p}=0.043, \mathrm{p}<0.05)$. The size of the difference between the means (mean difference $=-0.11,95 \% C I$ : -0.2217 to 0.0037 ) was very low (Cohen'd $=0.008$ ). To check the assumption of homogeneity, Levene's test was conducted and indicated equality variance was assumed $(F(504)=3.088, \mathrm{p}=0.079, \mathrm{p}>0.05)$.

\subsubsection{Age and Chinese Language Proficiency}

The associations of age and Chinese language proficiency with acculturative stress were determined using the Pearson product-moment correlation. Acculturative stress was found to be positively related to age $(\mathrm{r}=0.16, N=506, \mathrm{p}<$ $0.05)$ and negatively related language proficiency $(\mathrm{r}=-0.10, N=506, \mathrm{p}<0.05)$, 
delineating that the participants with younger ages and good Chinese language proficiency reported lower level of acculturative stress.

\subsubsection{Educational Status}

To observe whether acculturative scores were different across participants of different educational levels, a one-way between groups analysis of variance was carried out. Statistically significant difference was explored in acculturative stress scores for the three educational status groups $(F(2,503)=5.682, \mathrm{p}=0.004, \mathrm{p}<$ 0.01 ). The degree of association measured using eta squared was found to be 0.02 . As measured by Levene's test, the assumption of homogeneity was not violated $(F(2,503)=1.537, \mathrm{p}=0.216, \mathrm{p}<0.01)$. To see the specific differences between the groups, a further analysis, post-hoc test using Tukey HSD was conducted and the result indicated that the mean score for Bachelor students $(M=$ 2.14, $S D=0.56, \mathrm{p}=0.035)$ significantly differed from Master $(M=2.29, S D=$ $0.53)$ and Doctorate $(M=2.36, S D=0.60, \mathrm{p}=0.004)$ participant students. Meaning that Master and Doctorate international students experienced a higher level of acculturative stress than the Bachelors. However, the mean difference between Master and doctorate students was not found to be statistically significant, $\mathrm{p}>0.05$.

\subsection{Bivariate Correlation between Acculturative Stressors and Depression}

A Pearson's product moment correlation was run to determine the bivariate relationship between the subscales of acculturative stress and depressive symptoms. As presented in Table 3, the correlation results indicated that all acculturative stressors appeared to be significantly positively associated with depression. Among the components of acculturative stress, fear, miscellaneous and perceived hated demonstrated a stronger significant correlation with depression.

Table 3. Summary of Mean, SD, and Pearson's $r$ values for acculturative stressors and depression $(\mathrm{N}=506)$.

\begin{tabular}{|c|c|c|c|c|c|c|c|c|}
\hline Variables & 1 & 2 & 3 & 4 & 5 & 6 & 7 & 8 \\
\hline \multicolumn{9}{|l|}{ 1. Acculturative stress } \\
\hline 2. Discrimination & $0.85^{\star \star}$ & & & & & & & \\
\hline 3. Homesickness & $0.60^{\star *}$ & $0.34^{\star *}$ & & & & & & \\
\hline 4. Perceived Hate & $0.80^{\star *}$ & $0.67^{\star *}$ & $0.29^{* *}$ & & & & & \\
\hline 5. Fear & $0.77^{\star *}$ & $0.58^{\star *}$ & $0.29^{\star \star}$ & $0.66^{\star *}$ & & & & \\
\hline 6. Culture Shock & $0.68^{\star *}$ & $0.47^{\star *}$ & $0.50^{\star *}$ & $0.42^{\star *}$ & $0.47^{\star *}$ & & & \\
\hline 7. Guilt & $0.63^{\star *}$ & $0.39^{* *}$ & $0.44^{\star *}$ & $0.45^{\star *}$ & $0.49^{* *}$ & $0.40^{\star *}$ & & \\
\hline 8. Miscellaneous & $0.91^{\star *}$ & $0.74^{\star *}$ & $0.48^{\star *}$ & $0.67^{\star *}$ & $0.65^{\star *}$ & $0.57^{\star *}$ & $0.53^{\star *}$ & \\
\hline 9. Depression & $0.37^{\star \star}$ & $0.23^{\star *}$ & $0.24^{\star *}$ & $0.32^{\star *}$ & $0.37^{\star *}$ & $0.26^{\star *}$ & $0.30^{* *}$ & $0.34^{* *}$ \\
\hline
\end{tabular}

${ }^{* *}$ Correlation is significant at the 0.01 level (2-tailed). 


\section{Discussion}

The current study examined the primary sources of acculturative stress and how acculturative stress was associated with socio-demographic variables and depression with the help of t-test and analysis of variance, Pearson's product-moment correlation with a sample of 506 international university students. Students reported that homesickness, culture shock, and discrimination are among the top stress producing factors. Several students' demographic characteristics such as marital status, age, educational status, friendship with local students, Chinese language proficiency and prior travel experience appeared to be significantly associated with their acculturative stress scores. Similarly, a significant positive correlation between acculturative stress and depression was explored.

\subsection{Leading Sources of Acculturative Stress}

The study found all measured stressors contributing to the feeling of the acculturative stress of the students. However, homesickness, culture shock, and discrimination were found to be the first top three leading sources of acculturative stress among the students. A conceivable elucidation for this may be because of separation anxiety, meaning that leaving one's beloved families, friends, culture, and country behind and studying a new environment may impede students from normal functioning and adjustment. Similarly, students' feeling of uncertainty and confusion or cultural shock may be due to unfamiliarity to the new host culture especially when there is a significant difference between the two cultures. Lack of mutual cultural respect, prejudice, stereotype, and racism may exacerbate the acculturative difficulties of the international students. Several previous findings have also asserted that homesickness [12], culture shock [17] and discrimination [13] [51] are among the terrible challenges for international students in the host community.

\subsection{Association between Sociodemographics and Acculturative Stress}

Findings with respect to the association between acculturative stress and sociodemographics such as marital status and gender are not yet well settled and mixed up. In the present study, the level of acculturative stress was found to be significantly different for married and unmarried student participants, showing that married students experienced a higher level of acculturative stress than their counterparts. Even though this finding is consistent with several previous findings [32], there are other contradictory results, reported that unmarried individuals are more prone to acculturative stress [31]. Documented research findings concerning gender are mixed up and self-contradictory as well. For instance, according to Mahmood and Burke [52], male students reported higher acculturative stress than female students which challenges the finding that female students are more vulnerable to acculturative stress than males [53]. The 
present study, on the other hand, found no statistically significant association between gender and acculturative stress level and supported by several findings [8] [33]. Such controversial results might be due to lack of adequate acculturative studies and variation in samples studies.

Age was appeared to be positively correlated with acculturative stress, donating that older international students experience a higher level of stress than the younger ones. In line with the present finding, several supporting findings demonstrated that younger students experience lesser acculturative stress (e.g., [29] [54]). This may be because of the postulation that people effectively function in the process of socialization (e.g., learning language, norms, and values of the host community) in earlier ages [40].

Despite the limited evidence for the association between acculturative stress and educational level [33], the present finding indicated that undergraduate students face less acculturative difficulties than postgraduate participant students which parallels to the finding that Ph.D. students generally experience higher acculturative stress [55]. This seems due to the difference in academic assignment and engagements of the students. Bachelor degree students are generally required to acquire and construct basic understanding and knowledge of specific courses which may relatively be manageable than the academic activities of postgraduate students. Students are required to analyze knowledge in their master's degree and contribute new information to the scientific body of knowledge in their doctorate studies which perhaps put them into extra acculturative difficulties.

Several studies have also documented that financial difficulty is one of the leading sources of acculturative stress for international students [28]. The source of financial support may be the government of the host country in the form of scholarship or families (parents) of the students. As the amount of financial aid provided by the host government may not be sufficient to afford all the daily living expenses, scholarship students may face greater acculturative difficulties. It may be for this reason that the present study explored higher acculturative stress in scholarship students than self-supporting students. However, a different finding was also reported, revealing that self-support students undergo greater acculturative challenges [33]. The reason for this alteration may rest on variations in the parental financial background of the students, work permit and opportunities for international students in the host country and amount of stipend given to the scholarship students. Meaning that if the students have limited or are prohibited from part-time jobs, and yet the amount of stipend is not adequate, the scholarship students may also be stressed. On the other hand, if the self-supporting students have secured financial aid from their parents, they may not bother about financial issue.

Language difficulty has also invariably been reported as a source of acculturative stress, ascertaining that international students with poor local language proficiency in the host community are more likely to experience higher acculturative stress (e.g., [34] [56]). In congruence with the previous literature, the 
present result also found a significant negative correlation between acculturative stress and Chinese language proficiency, suggesting that students with good Chinese language skill better function in the process of acculturation. Likewise, the current study found that international students who are capable of establishing and maintaining a friendship with domestic students experienced less acculturative stress. This result appears to be consistent with previous studies that social networks diminish adjustment challenges and strengthen positive acculturative outcomes [35] [57]. When students actively engage in interpersonal social interactions with the local students and enlarge the horizon of their social network, they manage to learn and improve their cultural knowledge and understanding of the host society and thereby better adjust to the new environment.

\subsection{Relationship between Acculturative Stress and Depression}

Following the acculturative stress model of Berry [6], the present study examined the association between acculturative stress and depression and all acculturative stress components were found to be significantly associated with depression. Meaning that students with a high level of acculturative stress reported greater depressive symptoms. In line with the present finding, several research findings revealed that there is a positive relationship between acculturative stress and depression among general emigrants including international students' studies (e.g., [37] [58] [59]). It seems healthy and inevitable for individuals to undergo a stressful situation in the new environment. However, when the acculturative stress persists over time, it may lead to debilitating mental health problems such as depression, anxiety [25] especially in the absence of utilization effective stress coping strategies [60].

\subsection{Limitations and Future Directions}

The current study had several limitations. A possible limitation is that the study was a quantitative study relied on self-report questionnaires. Albeit many researchers extensively use questionnaires as a means of obtaining quantitative data, participants might show social desirability bias and lack of conscientious response in filling the questionnaire which may limit the accuracy of the findings. Therefore, the door for future studies is open to employ both qualitative and quantitative research designs and obtain triangulation of data to figure out acculturative difficulties accurately. The study was also limited to explore a correlational relationship between acculturative stress and sociodemographics and depression without establishing the causal relationships between the variables. Further, the study was a descriptive cross-sectional study measured all study variables at a particular point in time. Thus, as students' acculturative experiences are subject to change over time, a quasi-experimental longitudinal study could be conducted in future research endeavors to enhance the present findings and precisely and comprehensively map out the acculturative context of the interna- 
tional students. Finally, since participants for the present study were conveniently selected from the population, representativeness with respect to some of the sociodemographic factors may affect the results. Therefore, future studies could conduct a study using representative samples to endorse the findings of the study.

\subsection{Conclusions}

Despite the benefits that the global educational market provides for international students, it is also claimed to be a source of a wide range of adjustment difficulties and mental health problems. In connection with this claim, the study intended to unlock the major acculturative challenges that international students encounter in the host country and how these acculturative stressors are associated with their demographic characteristics and depression. The study explored that several factors contribute to students' acculturative stress. However, the principal acculturative stress-inducing factors are homesickness, culture shock, and discrimination. Besides, acculturative stress was found to be associated with students' sociodemographics and depressive symptoms.

Interestingly, older, married, graduate and postgraduate and scholarship students reported higher acculturative stress. On the other hand, good Chinese language skill, previous travel experience and friendship with local friends were found contributing to students' better functioning in the acculturation process and thereby minimize their experience of acculturative stress. Finally, students with higher acculturative stress reported higher depressive symptoms. The study underscores the need to understand and worth considering the individual characteristics and variation of the magnitude of the factors that contribute to adverse acculturative outcomes in providing support and mental health services for the acculturating student individuals in the host institutions.

\subsection{Implication}

The current study contributes to the scientific body of knowledge by examining the acculturative stressors and their linkage with personal characteristics and depression from individual perspectives. The study broadens the horizon of understanding and knowledge of international students, teachers, international students' affair coordinators, and administrators, counselors, and the host school communities as a whole about the specific acculturative challenges that international students encounter in the host community. Besides, the study provides information on how acculturative stress relates to students personal demographic characteristics and depressive symptoms. Consequently, having a comprehensive understanding of acculturative context of international students allows the stakeholders to create a suitable environment where students function in the arena of acculturation effectively. More importantly, counselors could make the best use of the present findings in their guidance and counseling programs by recognizing the significant acculturative stress causing factors and 
their impact on the mental health of the students. Accordingly, they could run programs which combat the main acculturative challenges and provide better mental health services. Additionally, the findings of the study could assist counselors to identify the sub-groups more prone to acculturative stress and provide additional professional assistance.

\section{Conflicts of Interest}

The author declares no conflicts of interest regarding the publication of this paper.

\section{References}

[1] Zha, Q. (2003) Internationalization of Higher Education: Towards a Conceptual Framework. Policy Futures in Education, 1, 248-270. https://doi.org/10.2304/pfie.2003.1.2.5

[2] Bevis, T.B. (2002) At a Glance: International Students in the United States. International. Educator, 11, 12-17.

[3] Smith, R.A. and Khawaja, N.G. (2011) A Review of the Acculturation Experiences of International Students. International Journal of Intercultural Relations, 35, 699-713. https://doi.org/10.1016/j.ijintrel.2011.08.004

[4] Bista, K. (2019) Exploring the Field: Understanding the International Student Experience. In: Bista, K., Ed., Global Perspectives on International Student Experiences in Higher, Routledge, New York, 1-16.

[5] Tummala-Narra, P. and Claudius, M. (2013) A Qualitative Examination of Muslim Graduate International Students' Experiences in the United States. International Perspectives in Psychology: Research, Practice, Consultation, 2, 132-147. https://doi.org/10.1037/ipp0000003

[6] Berry, J.W. (2006) Acculturative Stress. In: Wong, P.T.P. and Wong, L.C.J., Eds., Handbook of Multicultural Perspectives on Stress and Coping, Springer US, Boston, MA, 287-298. https://doi.org/10.1007/0-387-26238-5_12

[7] Berry, J.W. (2005) Acculturation: Living Successfully in Two Cultures. International Journal of Intercultural Relations, 29, 697-712. https://doi.org/10.1016/j.ijintrel.2005.07.013

[8] Mustaffa, C.S. and Ilias, M. (2013) Relationship between Students Adjustment Factors and Cross Cultural Adjustment: A Survey at the Northern University of Malaysia. Intercultural Communication Studies, 1, 279-300.

[9] Williams, C.L. and Berry, J.W. (1991) Primary Prevention of Acculturative Stress among Refugees: Application of Psychological Theory and Practice. American Psychologist, 46, 632-641. https://doi.org/10.1037/0003-066X.46.6.632

[10] Stroebe, M., Van Vliet, T., Hewstone, M. and Willis, H. (2002) Homesickness among Students in Two Cultures: Antecedents and Consequences. British Journal of Psychology, 93, 147-168. https://doi.org/10.1348/000712602162508

[11] Saravanan, C., Alias, A. and Mohamad, M. (2017) The Effects of Brief Individual Cognitive Behavioural Therapy for Depression and Homesickness among International Students in Malaysia. Journal of Affective Disorders, 220, 108-116. https://doi.org/10.1016/j.jad.2017.05.037

[12] Kegel, K. (2015) Homesickness and Psychological Distress in Asian International 
Students: The Potential Mediating Roles of Social Connectedness and Universal Diverse Orientation. Theses and Dissertations 2657. http://preserve.lehigh.edu/etd/2657

[13] Araujo, A.A.D. (2011) Adjustment Issues of International Students Enrolled in American Colleges and Universities: A Review of the Literature Higher Education Studies, 1, 2-8.

[14] Lee, J., Jon, J.-E. and Byun, K. (2016) Neo-Racism and Neo-Nationalism Within East Asia: The Experiences of International Students in South Korea. Journal of Studies in International Education, 21, 136-155. https://doi.org/10.1177/1028315316669903

[15] Ramos, M.R., Cassidy, C., Reicher, S. and Haslam, S.A. (2016) A Longitudinal Study of the Effects of Discrimination on the Acculturation Strategies of International Students. Journal of Cross-Cultural Psychology, 47, 401-420.

https://doi.org/10.1177/0022022116628672

[16] Nailevna, T.A. (2017) Acculturation and Psychological Adjustment of Foreign Students (the Experience of Elabuga Institute of Kazan Federal University). Procedia-Social and Behavioral Sciences, 237, 1173-1178. https://doi.org/10.1016/j.sbspro.2017.02.175

[17] Yang, Y., Zhang, Y. and Sheldon, K.M. (2018) Self-Determined Motivation for Studying Abroad Predicts Lower Culture Shock and Greater Well-Being among International Students: The Mediating Role of Basic Psychological Needs Satisfaction. International Journal of Intercultural Relations, 63, 95-104. https://doi.org/10.1016/j.ijintrel.2017.10.005

[18] Sandhu, D.S. (1994) An Examination of the Psychological Needs of the International Students: Implications for Counselling and Psythotherapy. International Journal for the Advancement of Counselling, 17, 229-239. https://doi.org/10.1007/BF01407739

[19] Stephan, W.G. and Stephan, C.W. (1996) Predicting Prejudice. International Journal of Intercultural Relations, 20, 409-426. https://doi.org/10.1016/0147-1767(96)00026-0

[20] Sandhu, D.S. and Asrabadi, B.R. (1994) Development of an Acculturative Stress Scale for International Students: Preliminary Findings. Psychological Reports, 75, 435-448. https://doi.org/10.2466/pr0.1994.75.1.435

[21] Arslan, G., Ayranci, U., Unsal, A. and Arslantas, D. (2009) Prevalence of Depression, Its Correlates among Students, and Its Effect on Health-Related Quality of Life in a Turkish University. Upsala Journal of Medical Sciences, 114, 170-177. https://doi.org/10.1080/03009730903174339

[22] Pilgrim, D., Rogers, A. and Pescosolido, B. (2011) The SAGE Handbook of Mental Health and Illness. London. http://sk.sagepub.com/reference/hdbk_mentalhealth

[23] Beiter, R., Nash, R., McCrady, M., Rhoades, D., Linscomb, M., Clarahan, M. and Sammut, S. (2015) The Prevalence and Correlates of Depression, Anxiety, and Stress in a Sample of College Students. Journal of Affective Disorders, 173, 90-96. https://doi.org/10.1016/j.jad.2014.10.054

[24] Eskanadrieh, S., Liu, Y., Yamashina, H., Kono, K., Arai, A.B., Lee, R. and Tamashiro, H. (2012) Depressive Symptoms among International University Students in Northern Japan: Prevalence and Associated Factors. Journal of International Health, 27, 165-170.

[25] Berry, J.W., Kim, U., Minde, T. and Mok, D. (1987) Comparative Studies of Acculturative Stress. The International Migration Review, 21, 491-511. 
https://doi.org/10.1177/019791838702100303

[26] Chen, C.P. (1999) Professional Issues: Common Stressors among International College Students: Research and Counseling Implications. Journal of College Counseling, 2, 49-65. https://doi.org/10.1002/j.2161-1882.1999.tb00142.x

[27] Desa, A., Yusooff, F. and Kadir, N.B.A. (2012) Acculturative Stress among International Postgraduate Students at UKM. Procedia-Social and Behavioral Sciences, 59, 364-369. https://doi.org/10.1016/j.sbspro.2012.09.287

[28] Nasirudeen, A.M.A., Josephine, K.W.N., Adeline, L.L.C., Seng, L.L. and Ling, H.A. (2014) Acculturative Stress among Asian International Students in Singapore. Journal of International Students, 4, 363-373. https://files.eric.ed.gov/fulltext/EJ1054803.pdf

[29] Berry, J.W. (1997) Immigration, Acculturation, and Adaptation. Applied Psychology: An International Review, 46, 5-34. https://doi.org/10.1111/j.1464-0597.1997.tb01087.x

[30] Yeh, C.J. and Inose, M. (2003) International Students' Reported English Fluency, Social Support Satisfaction, and Social Connectedness as Predictors of Acculturative Stress. Counselling Psychology Quarterly, 16, 15-28. https://doi.org/10.1080/0951507031000114058

[31] Ahalya, K. and Berry, J.W. (1992) Acculturative Stress and Acculturation Attitudes among Indian Immigrants to the United States. Psychology and Developing Societies, 4, 187-212. https://doi.org/10.1177/097133369200400206

[32] Yu, B., Chen, X., Li, S., Liu, Y., Jacques-Tiura, A.J. and Yan, H. (2014) Acculturative Stress and Influential Factors among International Students in China: A Structural Dynamic Perspective. PLoS ONE, 9, e96322. https://doi.org/10.1371/journal.pone.0096322

[33] Akhtar, M. and Kröner-Herwig, B. (2015) Acculturative Stress among International Students in Context of Socio-Demographic Variables and Coping Styles. Current Psychology, 34, 803-815. https://doi.org/10.1007/s12144-015-9303-4

[34] Cetinkaya-Yildiz, E., Cakir, S.G. and Kondakci, Y. (2011) Psychological Distress among International Students in Turkey. International Journal of Intercultural Relations, 35, 534-539. https://doi.org/10.1016/j.ijintrel.2011.04.001

[35] Hendrickson, B., Rosen, D. and Aune, R.K. (2011) An Analysis of Friendship Networks, Social Connectedness, Homesickness, and Satisfaction Levels of International Students. International Journal of Intercultural Relations, 35, 281-295. https://doi.org/10.1016/j.ijintrel.2010.08.001

[36] Chung, H. and Epstein, N.B. (2014) Perceived Racial Discrimination, Acculturative Stress, and Psychological Distress among Asian Immigrants: The Moderating Effects of Support and Interpersonal Strain from a Partner. International Journal of Intercultural Relations, 42, 129-139. https://doi.org/10.1016/j.ijintrel.2014.04.003

[37] Liu, Y., Chen, X., Li, S., Yu, B., Wang, Y. and Yan, H. (2016) Path Analysis of Acculturative Stress Components and Their Relationship with Depression among International Students in China. Stress and Health, 32, 524-532. https://doi.org/10.1002/smi.2658

[38] Rice, K.G., Choi, C.-C., Zhang, Y., Morero, Y.I. and Anderson, D. (2012) Self-Critical Perfectionism, Acculturative Stress, and Depression among International Students. The Counseling Psychologist, 40, 575-600. https://doi.org/10.1177/0011000011427061

[39] Hunley, H.A. (2010) Students' Functioning while Studying Abroad: The Impact of Psychological Distress and Loneliness. International Journal of Intercultural Rela- 
tions, 34, 386-392. https://doi.org/10.1016/j.ijintrel.2009.08.005

[40] Heine, J.S. (2016) Cultural Psychology. W. W. Norton \& Company, New York.

[41] Tiwari, R. (2017) Acculturative Stress and Mental Health of International Students: A Systematic Review. The International Journal of Indian Psychology, 4, 112-121.

[42] Saad, K.A. (2015) Mental Health and Psychological Variables among International Students in the UK: A Comparative Stud. International Journal of Humanities Social Sciences and Education, 2, 42-48. https://www.arcjournals.org/pdfs/ijhsse/v2-i6/5.pdf

[43] Wen, W., Hu, D. and Hao, J. (2017) International Students' Experiences in China: Does the Planned Reverse Mobility Work? International Journal of Educational Development, 61, 204-212.

[44] Babbie, E. (2010) The Practice of Social Research. 12th Edition, Wadsworth Cengage, Belmont.

[45] Constantine, M.G., Okazaki, S. and Utsey, S.O. (2004) Self-Concealment, Social Self-Efficacy, Acculturative Stress, and Depression in African, Asian, and Latin American International College Students. American Journal of Orthopsychiatry, 74, 230-241. https://doi.org/10.1037/0002-9432.74.3.230

[46] Radloff, L.S. (1977) The CES-D Scale: A Self-Report Depression Scale for Research in the General Population. Applied Psychological Measurement, 1, 385-401. https://doi.org/10.1177/014662167700100306

[47] Wei, M., Heppner, P.P., Mallen, M.J., Ku, T.-Y., Liao, K.Y.-H. and Wu, T.-F. (2007) Acculturative Stress, Perfectionism, Years in the United States, and Depression among Chinese International Students. Journal of Counseling Psychology, 54, 385-394. https://doi.org/10.1037/0022-0167.54.4.385

[48] Field, A. (2009) Discovering Statistics Using SPSS. 3rd Edition, SAGE, London.

[49] Gravetter, F. and Wallnau, L. (2014) Essentials of Statistics for the Behavioral Sciences. 8th Edition, Wadsworth, Belmont.

[50] Cohen, J. (1988) Statistical Power Analysis for the Behavioral Sciences. L. Erlbaum Associates, Hillsdale.

[51] Jones, E. (2017) Problematising and Reimagining the Notion of "International Student Experience". Studies in Higher Education, 42, 933-943. https://doi.org/10.1080/03075079.2017.1293880

[52] Mahmood, H. and Burke, M.G. (2018) Analysis of Acculturative Stress and Sociocultural Adaptation among International Students at a Non-Metropolitan University. Journal of International Student, 8, 284-307.

[53] Msengi, I.G. (2003) Sources of Stress and Its Impact on Health Behaviors and Academic Performance of International Students at Comprehensive Midwestern University. International Journal of Global Health and Health Disparities, 5, 55-69. https://scholarworks.uni.edu/cgi/viewcontent.cgi?article=1035\&context=ijghhd

[54] Ashur, T.S. and Jamil, A.T. (2014) Stress among International Postgraduate Students at University Kebangsaan Malaysia Medical Centre (UKMMC). Malaysian Journal of Public Health Medicine, 14, 21-33. https://www.researchgate.net/publication/279178457

[55] Ye, H.D. and Juni, M.H. (2018) Predictors of Acculturative Stress among International Postgraduate Students in Malaysia Public University. International Journal of Public Health and Clinical Sciences, 5, 155-172. http://publichealthmy.org/ejournal/ojs2/index.php/ijphcs/article/view/647/477

[56] Bartlett, L., Mendenhall, M. and Ghaffar-Kucher, A. (2017) Culture in Accultura- 
tion: Refugee Youth's Schooling Experiences in International Schools in New York City. International Journal of Intercultural Relations, 60, 109-119.

https://doi.org/10.1016/j.ijintrel.2017.04.005

[57] Sullivan, C. and Kashubeck-West, S. (2015) The Interplay of International Students' Acculturative Stress, Social Support, and Acculturation Modes. Journal of International Students, 5, 1-11.

[58] Brunsting, N.C., Zachry, C. and Takeuchi, R. (2018) Predictors of Undergraduate International Student Psychosocial Adjustment to US Universities: A Systematic Review from 2009-2018. International Journal of Intercultural Relations, 66, 22-33. https://doi.org/10.1016/j.ijintrel.2018.06.002

[59] Lumley, M., Katsikitis, M. and Statham, D. (2018) Depression, Anxiety, and Acculturative Stress among Resettled Bhutanese Refugees in Australia. Journal of Cross-Cultural Psychology, 49, 1269-1282. https://doi.org/10.1177/0022022118786458

[60] Lazarus, R.S. and Folkman, S. (1984) Stress, Appraisal, and Coping. Springer Publishing Company, New York. 